\title{
Evidence That Increased Hippocampal Expression of the Cytokine Interleukin-1 $\beta$ Is a Common Trigger for Age- and Stress-Induced Impairments in Long-Term Potentiation
}

\author{
Ciara A. Murray and Marina A. Lynch \\ Department of Physiology, Trinity College, Dublin 2, Ireland
}

Several cytokines and their receptors are identified in brain; one of these is the proinflammatory cytokine interleukin- $1 \beta$ that is synthesized and released from neurons and glia in response to stress or insult. Among the actions of interleukin- $1 \beta$ is its ability to inhibit long-term potentiation in the hippocampus in vitro, an action that mimics one of the consequences of stress and age. It has been shown that the concentration of interleukin- $1 \beta$ in brain tissue is increased in neurodegenerative conditions, and recent evidence from our laboratory has indicated an increase in the concentration of interleukin- $1 \beta$ in the hippocampus of aged rats. These observations led us to consider that the underlying common cause of impaired long-term potentiation in aged and stressed rats might be increased endogenous interleukin- $1 \beta$ concentration in hippocampus. The data presented here indicate that there was an inverse relationship between concentration of interleukin- $1 \beta$ in the dentate gyrus and long-term potentiation in perforant path $\rightarrow$ granule cell synapses in aged rats, stressed rats, and rats pretreated with interleukin-1 $\beta$. The evidence suggested that the cytokine induces formation of reactive oxygen species that triggers lipid peroxidation in vivo, as well as in vitro, and that these changes lead to depletion of membrane arachidonic acid that correlates with impaired long-term potentiation. We propose that three theories of aging, the glucocorticoid theory, the membrane theory, and the free radical theory, constitute three facets of age with one underlying trigger: an increase in the endogenous concentration of interleukin- $1 \beta$ in hippocampus.

Key words: long-term potentiation; dentate gyrus; interleukin$1 \beta$; aging; stress; lipid peroxidation; arachidonic acid; reactive oxygen species
Recent evidence indicates a central role for the proinflammatory cytokine interleukin-1 $\beta$ (IL-1 $\beta$ ). For example, IL-1 modulates gastric function (Mo et al., 1996) and appetite (Plata-Salaman et al., 1988), mediates fever (Fontana et al., 1984; Dascombe et al., 1989), and stimulates the hypothalamo-pituitary-adrenal axis (Sapolsky et al., 1987). IL-1 is synthesized by neuronal (Farrar et al., 1987; Lechan et al., 1990) and/or glial cells (Giulian et al., 1986; Yao et al., 1992) and is released in response to injury, insult, and stress (Rothwell and Hopkins, 1995). It is therefore not surprising that increased expression of IL-1 $\beta$ has been associated with neurodegenerative conditions (Griffin et al., 1989).

Autoradiographic (Takao et al., 1990; Ban et al., 1991; Ericsson et al., 1995), immunohistochemical (Lechan et al., 1990), and in situ hybridization studies (Cunningham et al., 1992; Parnet et al., 1994) indicate a high density of IL-1 receptors in hippocampus, and consistent with this are several effects of exogenously applied IL-1; it inhibits calcium influx (Plata-Salaman and ffrenchMullen, 1994; Murray et al., 1997), protein kinase C (Murray et al., 1997), release of acetylcholine (Rada et al., 1991), and glutamate (Murray et al., 1997) in hippocampus. IL-1 $\beta$ also inhibits long-term potentiation (LTP) in vitro (Katsuki et al., 1990; Bellinger et al., 1993; Cunningham et al., 1996), although the mechanism is unknown. One possibility is that IL-1 induces formation of reactive oxygen species in brain as in other cell types (Nathan and Tsunawaki, 1986; Sumoski et al., 1989), which is consistent with the finding that free radicals inhibit LTP (Pellmar

Received Oct. 29, 1997; revised Jan. 30, 1998; accepted Feb. 5, 1998.

This work was supported by the Health Research Board of Ireland, Forbairt, and the Provost's Academic Development Fund, Trinity College.

Correspondence should be addressed to Dr. Lynch at the above address.

Copyright $\odot 1998$ Society for Neuroscience $0270-6474 / 98 / 182974-08 \$ 05.00 / 0$ et al., 1991). Free radicals also induce oxidation of polyunsaturated fatty acids, such as arachidonic acid (Nagy, 1994), decreasing membrane concentrations and thereby inhibiting LTP (Lynch and Voss, 1994; McGahon et al., 1997).

Plasma levels of corticosterone that increase with age also correlate with impairments in LTP (Landfield et al., 1978a; Landfield and Eldridge, 1994; Bodnoff et al., 1995) and with cell loss (Landfield et al., 1978b). These observations form the basis of the glucocorticoid hypothesis of age-related neurodegeneration (Landfield and Eldridge, 1994). However, free radicals also play a role in neuronal cell death (Choi and Yu, 1994; Nagy, 1994), supporting the hypothesis that age-related neuronal deficits result from oxidative damage (Harman, 1956). Aspects of both hypotheses are significant in the context that IL- $1 \beta$ stimulates secretion of corticotropin-releasing factor from the hypothalamus (Sapolsky et al., 1987), the hallmark of stress and a feature of aging (Landfield and Eldridge, 1994), and induces lipid peroxidation in hippocampal tissue (Lynch, 1997), which may explain the age-related decrease in membrane arachidonic acid (Lynch and Voss, 1994). In the context of these observations, the finding that there is an age-related increase in IL- $1 \beta$ concentration in whole hippocampus (Murray and Lynch, 1997) is particularly salient.

The objective of this study was to investigate the mechanism underlying the inhibitory effect of IL- $1 \beta$ on LTP and therefore address the hypothesis that increased concentration of IL- $1 \beta$ might explain the impairment of LTP in aged and stressed rats.

\section{MATERIALS AND METHODS}

Male Wistar rats obtained from Charles River were used in these experiments. Rats were kept at $22-23^{\circ} \mathrm{C}$ on a $12 \mathrm{hr}$ light/dark cycle and 
housed in groups of two or three for aged animals or six for young animals except in one series of experiments. In this experiment 12 rats were housed in two groups of six for $10 \mathrm{~d}$, and at the end of this period six of these rats were separated and individually housed for 1 week before the experiment.

Induction of LTP in perforant path $\rightarrow$ granule cell synapses in vivo. LTP was induced as described previously (McGahon and Lynch, 1996). Rats were anesthetized by intraperitoneal injection of urethane. The mean \pm SEM dose of urethane required to induce anesthesia (as assessed by the absence of a pedal reflex) in young animals was $2.09 \pm 0.12 \mathrm{gm} / \mathrm{kg}$ and $1.70 \pm 0.12 \mathrm{gm} / \mathrm{kg}$ in aged animals. Animals were placed in a head holder in a stereotaxic frame. At this time, some rats were injected intraventricularly with either IL-1 $\beta(10 \mu \mathrm{l}, 3.5 \mathrm{ng} / \mathrm{ml})$ or saline $(10 \mu \mathrm{l})$. Experiments were not performed in a double-blind manner. A window of skull was removed to allow placement of recording and stimulating electrodes in the molecular layer of the dentate gyrus $(2.5 \mathrm{~mm}$ lateral and $3.9 \mathrm{~mm}$ posterior to bregma) and perforant path, respectively (angular bundle, $4.4 \mathrm{~mm}$ lateral to lambda). The depth of the electrodes was adjusted to obtain maximal responses in the cell body region, and the stimulus strength chosen was that at which a spike appeared. Test shocks at the rate of one every $30 \mathrm{sec}$ were delivered for $10 \mathrm{~min}$ before tetanic stimulation, and then LTP was induced unilaterally in perforant path $\rightarrow$ granule cell synapses by delivery of three high-frequency trains of stimuli $(250 \mathrm{~Hz}$ for $200 \mathrm{msec}$ ) at $30 \mathrm{sec}$ intervals. Stimulation at test shock frequency resumed, and recordings continued for the remaining $40 \mathrm{~min}$ of the experiment. In the experiments in which rats received an intraventricular injection, a 30 min period elapsed before electrophysiological recordings commenced. At the end of the electrophysiological recording period, rats were killed by decapitation, and in some experiments blood was collected for analysis of serum corticosterone. The hippocampus was removed, and the tetanized and untetanized dentate gyri were dissected on ice and cross-chopped into slices $(350 \times 350 \mu \mathrm{m})$ using a McIlwain tissue chopper. All analyses (except circulating corticosteroids) were performed on samples of dentate gyrus. Individual samples were frozen in $1 \mathrm{ml}$ of Krebs' solution (in mM: $\mathrm{NaCl} 136, \mathrm{KCl} 2.54, \mathrm{KH}_{2} \mathrm{PO}_{4} 1.18$, $\mathrm{MgSO}_{4} \cdot 7 \mathrm{H}_{2} \mathrm{O}, 1.18, \mathrm{NaHCO}_{3} 16$, glucose 10 , and $\mathrm{CaCl}_{2} 1.13$ ) containing $10 \%$ dimethylsulfoxide according to the method of Haan and Bowen (1981). Thawed slices were rinsed three times in fresh buffer and homogenized in $200 \mu \mathrm{l}$ of fresh Krebs' solution for analysis of membrane arachidonic acid concentration, in $40 \mathrm{~mm}$ Tris- $\mathrm{HCl}, \mathrm{pH}$ 7.4, for analysis of reactive oxygen species production, and in distilled water for analysis of lipid peroxidation.

Analysis of IL-1 $\beta$ concentration. We used an ELISA for quantitative analysis of IL-1 $\beta$ (DuoSet ELISA development system, Genzyme). Ninety-six-well plates were coated with $100 \mu \mathrm{l}$ of capture antibody (monoclonal hamster anti-mouse IL- $1 \beta$ antibody; $2.0 \mu \mathrm{g} / \mathrm{ml}$ final concentration, diluted in $0.1 \mathrm{M}$ sodium carbonate buffer, $\mathrm{pH} 9.5$ ) and incubated overnight at $4^{\circ} \mathrm{C}$. Samples were washed several times with PBS containing $0.05 \%$ Tween 20 (PBS-Tween) and then blocked for $2 \mathrm{hr}$ at $37^{\circ} \mathrm{C}$ with $250 \mu \mathrm{l}$ of blocking buffer in PBS, $\mathrm{pH} 7.3$ (0.1 M with $4 \%$ bovine serum albumin). Blocking buffer was aspirated, and aliquots $(100 \mu \mathrm{l})$ of samples or IL-1 $\beta$ standards $(0-1000 \mathrm{pg} / \mathrm{ml})$ were added to each well and incubated for $1 \mathrm{hr}$ at $37^{\circ} \mathrm{C}$. Plates were washed, secondary antibody (biotinylated polyclonal rabbit anti-mouse IL-1 $\beta$ antibody; $100 \mu \mathrm{l}$ ) was added to each well, and incubation continued for $1 \mathrm{hr}$ at $37^{\circ} \mathrm{C}$. The plates were then washed, and $100 \mu \mathrm{l}$ of detection agent (horseradish peroxidase-conjugated streptavidin; 1:1000 dilution in PBS-Tween and $1 \%$ bovine serum albumin) was added to each well, incubation continued for $15 \mathrm{~min}$ more at $37^{\circ} \mathrm{C}$, and plates were again washed. Aliquots of substrate (100 $\mu$ l, tetramethylbenzidine liquid substrate; Sigma, Poole, UK) were added, and the plates were incubated at room temperature for $10 \mathrm{~min}$. The reaction was stopped by adding $100 \mu \mathrm{l}$ of $\mathrm{H}_{2} \mathrm{SO}_{4}(1 \mathrm{M})$, and absorbance was read at $450 \mathrm{~nm}$ within $30 \mathrm{~min}$.

Analysis of lipid peroxidation. Lipid peroxidation was assessed by measurement of malondialdehyde (MDA), an intermediate in lipid peroxidation, by a modification of the method of Ohkawa et al. (1979). Briefly, thawed slices were homogenized in ice-cold distilled water, and aliquots $(30 \mu \mathrm{l})$ of homogenate were incubated at $37^{\circ} \mathrm{C}$ for $60 \mathrm{~min}$, after which time $8.1 \%$ SDS $(30 \mu \mathrm{l}), 20 \%$ acetic acid, $\mathrm{pH} 3.5$ with $\mathrm{NaOH}(225 \mu \mathrm{l})$, and $0.8 \%(\mathrm{w} / \mathrm{v})$ thiobarbituric acid $(225 \mu \mathrm{l})$ were added. The volume was adjusted to $600 \mu \mathrm{l}$ with distilled water, and the samples were incubated for $60 \mathrm{~min}$ more at $95^{\circ} \mathrm{C}$. The samples were cooled, and the absorbance was measured at $532 \mathrm{~nm}$. Lipid peroxidation was determined from a standard curve of 1,1,3,3-tetramethoxypropane $(0-100 \mu \mathrm{M})$ and expressed as nanomoles of MDA per milligram of protein. In the case of aged rats, values were expressed as micromoles of MDA per milligram of wet weight, because protein concentrations per unit of wet weight were reduced in aged rats compared with young rats. Protein concentration was analyzed according to the method of Bradford (1976).

Analysis of arachidonic acid concentration. Arachidonic acid concentration was assessed as described previously (Miwa et al., 1986). Briefly, fatty acids were extracted into chloroform/methanol $(2: 1 \mathrm{v} / \mathrm{v} ; 1 \mathrm{ml})$ by vigorous shaking for $10 \mathrm{~min}$, followed by centrifugation at $1000 \times g$ for 5 min to separate the phases. The aqueous layer was discarded, and the chloroform phase was evaporated under nitrogen and resuspended in ethanol for analysis. Arachidonic acid was analyzed as its 2-nitrophenylhydrazine (NPH) derivative by reverse-phase HPLC. Fatty acids were derivatized by adding 2-NPH-HCl solution $[0.02 \mathrm{M}$ 2-nitrophenylhydrazine- $\mathrm{HCl}$ in $0.25 \mathrm{M} \mathrm{HCl}$-ethanol (1:1, v/v)] and EDC solution [(1-ethyl-3-(3-dimethylaminopropyl)carbodiimide hydrochloride); $0.25 \mathrm{M}$ in ethanol mixed in equal volumes with $3 \%$ ethanolic pyridine] and incubated at $60^{\circ} \mathrm{C}$ for $20 \mathrm{~min}$. After addition of potassium hydroxide $(15 \% \mathrm{w} / \mathrm{v}$ in methanol/water, 80:20) samples were incubated at $60^{\circ} \mathrm{C}$ for $15 \mathrm{~min}$ and cooled in running water. Derivatives were concentrated; $n$-hexane and phosphate buffer $(0.033 \mathrm{M}, \mathrm{pH} 6.4$, in $0.5 \mathrm{M}$ $\mathrm{HCl}$ ) were added, samples were vortex-mixed for $30 \mathrm{sec}$ and centrifuged for $5 \mathrm{~min}$ at $1500 \times \mathrm{g}$, and the hexane phase was evaporated to dryness under nitrogen. For HPLC analysis, samples were resuspended in methanol and injected onto a Intersil C18 column, and fatty acid derivatives were separated in isocratic mode with a mobile phase of $85 \%$ acetonitrile and $15 \%$ water (maintained at $\mathrm{pH} 4.5$ with $\mathrm{HCl}$ ) and detected by ultraviolet spectroscopy at $230 \mathrm{~nm}$. Arachidonic acid concentrations were estimated using the external standard method and were expressed as micromoles per milligram of wet weight.

Analysis of reactive oxygen species formation. Formation of reactive oxygen species was assessed by the method of Lebel and Bondy (1990), which relies on the measurement of 2' $7^{\prime}$-dichlorofluorescein (DCF), the oxidized fluorescent product of $2^{\prime} 7^{\prime}$-dichlorofluorescin diacetate (DCFH-DA). Thawed slices were homogenized in $1 \mathrm{ml}$ of ice-cold Tris buffer $(40 \mathrm{~mm}, \mathrm{pH} 7.4)$ and incubated at $37^{\circ} \mathrm{C}$ for $15 \mathrm{~min}$ in the presence of DCFH-DA (10 $\mu \mathrm{l} ; 5 \mu \mathrm{M}$ from a stock of $500 \mu \mathrm{M}$ in methanol). To terminate the reaction, the dye-loaded suspensions were centrif uged at $13,000 \times \mathrm{g}$ for $8 \mathrm{~min}$ at $4^{\circ} \mathrm{C}$, and the pellets were resuspended in $2 \mathrm{ml}$ of

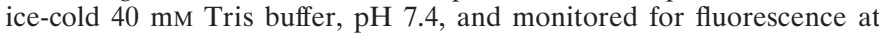
$37^{\circ} \mathrm{C}$ with the excitation wavelength at $488 \mathrm{~nm}$ and the emission wavelength at $525 \mathrm{~nm}$. Reactive oxygen species formation in the unknown samples was estimated from a DCF standard curve $(0.05-1 \mu \mathrm{M})$, and results were expressed as nanomoles per milligram of wet weight per min.

Analysis of circulating corticosterone concentration. Circulating corticosterone concentration in serum was determined by radioimmunoassay (ImmunoChem double-antibody corticosterone ${ }^{125}$ I RIA kit, ICN Biomedicals). Serum collected at the end of the electrophysiological recording period was diluted in phosphosaline gelatin buffer, $\mathrm{pH} 7.0$, containing rabbit $\gamma$-globulins, and incubated with $\left[{ }^{125} \mathrm{I}\right]$ corticosterone and anticorticosterone for $2 \mathrm{hr}$ at room temperature. Antibody-bound corticosterone was precipitated using polyethylene glycol and goat anti-rabbit $\gamma$-immunoglobulins in Tris buffer, and samples were centrifuged at $1000 \times g$ for 15 min and counted in a gamma counter. [ $\left.{ }^{125} \mathrm{I}\right]$ Corticosterone in the samples was assessed with reference to a standard curve and expressed as micrograms per milliliter of serum corrected for nonspecific binding.

\section{RESULTS}

We analyzed the effect of intraventricularly administered IL- $1 \beta$ $(3.5 \mathrm{ng} / \mathrm{ml}, 10 \mu \mathrm{l})$ on synaptic responses and on LTP in perforant path $\rightarrow$ granule cell synapses. IL- $1 \beta$ did not affect the mean EPSP slope recorded in the $10 \mathrm{~min}$ period before tetanic stimulation $(1.22 \pm 0.12 \mathrm{mV} / \mathrm{msec}$ in saline-treated rats vs $1.23 \pm 0.12$ $\mathrm{mV} / \mathrm{msec}$ in IL- $\beta$-treated rats; mean \pm SEM) but decreased the amplitude of the response $(4.17 \pm 0.25 \mathrm{mV}$ vs $3.11 \pm 0.08 \mathrm{mV}$; $p<0.05$, Student's $t$ test). Analysis of the effect of tetanic stimulation indicated that the immediate increase in EPSP (i.e., in the 2 min period immediately after tetanic stimulation) was slightly, but not significantly, attenuated by pretreatment with IL-1 $\beta$ (Fig. 1b). In contrast, intraventricular injection of IL-1 $\beta$ significantly inhibited the long-lasting increase in EPSP; the mean \pm SEM percentage changes in EPSP slopes in the last $5 \mathrm{~min}$ 
(a)

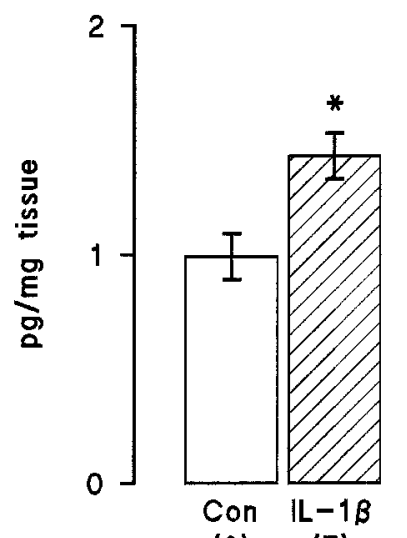

(6) (7) (b)

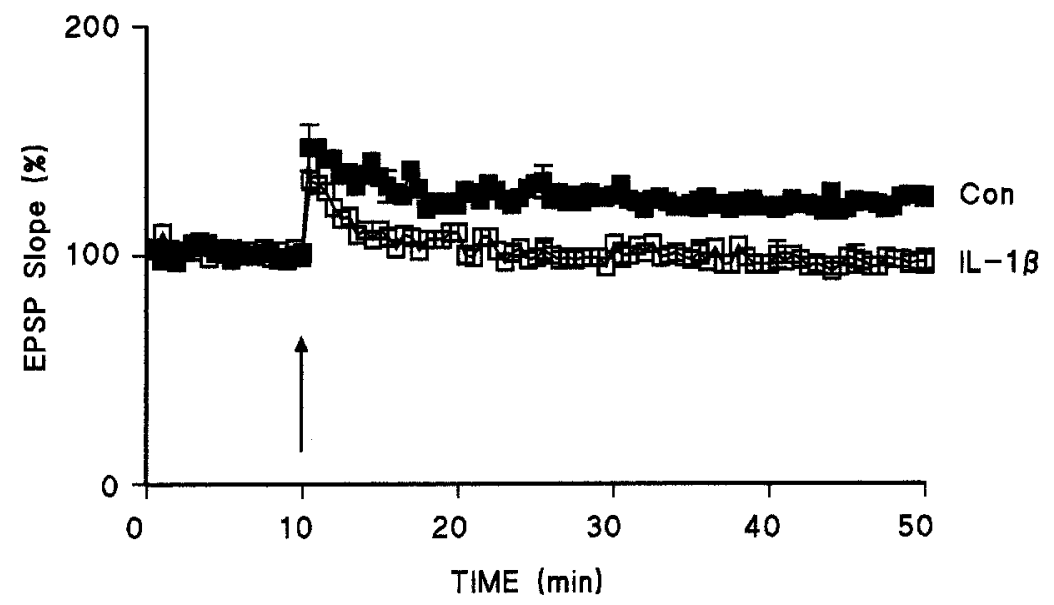

Figure 1. IL-1 $\beta$ concentration in dentate gyrus is increased and LTP is compromised after intraventricular injection of IL-1 $\beta$. $a$, IL-1 $\beta$ concentration (picograms per milligrams of tissue) in dentate gyrus was significantly increased ( $p<0.01$, Student's $t$ test; hatched bars) after intraventricular injection of IL-1 $\beta(10 \mu \mathrm{l}, 3.5 \mathrm{ng} / \mathrm{ml}) 30 \mathrm{~min}$ before recording commenced compared with saline injection (open bars). Values are mean \pm SEM. The number of observations is given in parentheses. $b$, Induction of LTP was not significantly affected by pretreatment with IL- $1 \beta$, but EPSP slope decreased to baseline levels $\sim 20$ min after tetanic stimulation (arrow). Values are given as mean percent of change in the slope of the EPSP over a 50 min period $(n=7$ in both groups). Error bars indicating SE are included at 5 min intervals; in some instances these are so small as to be obscured by the symbols.

of the experiment compared with the 5 min period immediately before tetanic stimulation were $120.47 \pm 1.39 \%$ and $97.27 \pm$ $5.11 \%$ in the saline-treated $(n=6)$ and IL- $1 \beta$-treated $(n=7)$ rats, respectively ( $p<0.01$, Student's $t$ test). Figure $1 a$ indicates that intraventricular injection of IL- $1 \beta$ led to a significant increase in the concentration of the cytokine in dentate gyrus $\sim 80$ min after injection ( $p<0.01$, Student's $t$ test).

We used a similar stimulus strength to evoke responses in aged and young rats in this series of experiments (mean \pm SEM, $3.27 \pm 0.21$ and $4.29 \pm 0.54 \mathrm{~V}$ in young and aged rats, respectively; see Materials and Methods). Under these circumstances, there was no significant difference between the mean EPSP slope recorded in the 10 min period before tetanic stimulation in the young and aged rats $(1.14 \pm 0.08$ and $0.96 \pm 0.09 \mathrm{mV} / \mathrm{msec}$, respectively), but the mean amplitude of the response was significantly decreased with age $(3.51 \pm 0.26$ and $1.90 \pm 0.16 \mathrm{mV}$, respectively; $p<0.05$, Student's $t$ test). Figure $2 b$ shows that the immediate increase in EPSP slope in the 2 min immediately after tetanic stimulation was slightly, but not significantly, attenuated in 22-month-old animals compared with 4-month-old animals. There was a marked age-related effect on maintenance of LTP; the data indicated that the mean percentage changes in EPSP slope in the last $5 \mathrm{~min}$ of the experiment compared with the $5 \mathrm{~min}$ immediately before tetanic stimulation were $134.27 \pm 2.67$ and $107.99 \pm 2.92 \%$ in the 4-month-old $(n=7)$ and 22-month-old $(n=10)$ rats, respectively (Fig. $2 b ; p<0.01$, Student's $t$ test). (a)

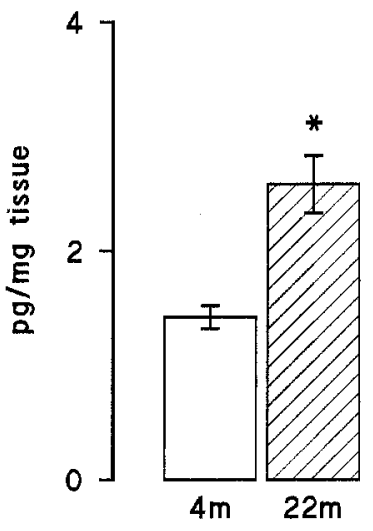

(6)

(7) (b)

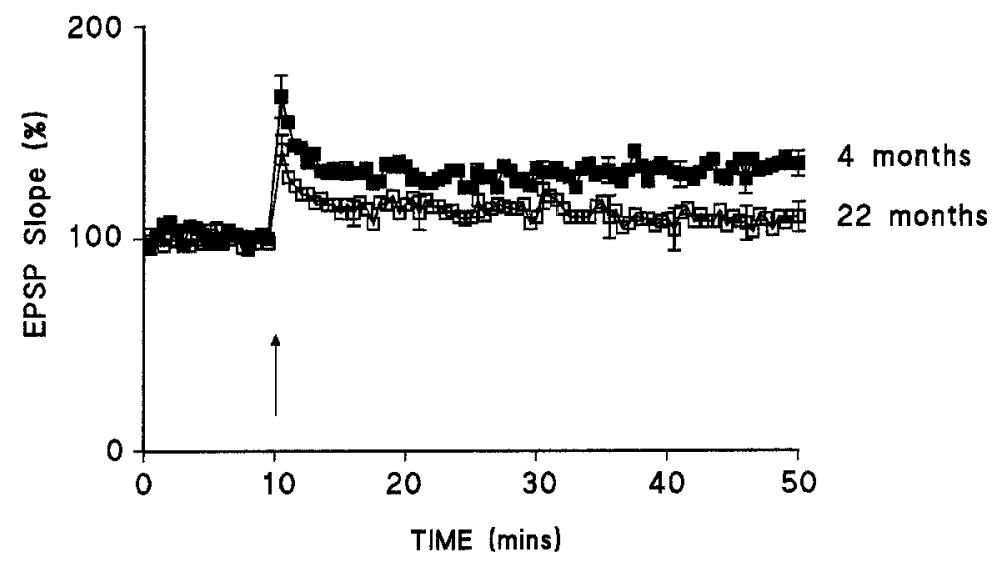

Figure 2. IL-1 $\beta$ concentration in dentate gyrus is increased and LTP is compromised in 22-month-old compared with 4-month-old rats. $a$, IL-1 $\beta$ concentration (picograms per milligram of tissue) in dentate gyrus was significantly increased $(p<0.01$, Student's $t$ test; hatched bars) in aged rats compared with young rats (open bars). Values are mean \pm SEM, and the number of observations is given in parentheses. $b$, The mean percent of change in EPSP slope immediately after the tetanus was similar in both groups of rats, but EPSP slope in the last 5 min of the experiment was significantly reduced in the aged rats $(n=10)$ compared with the young rats $(n=7 ; p<0.01$, Student's $t$ test $)$. Error bars indicating SE are included at 5 min intervals; in some instances these are so small as to be obscured by the symbols. 


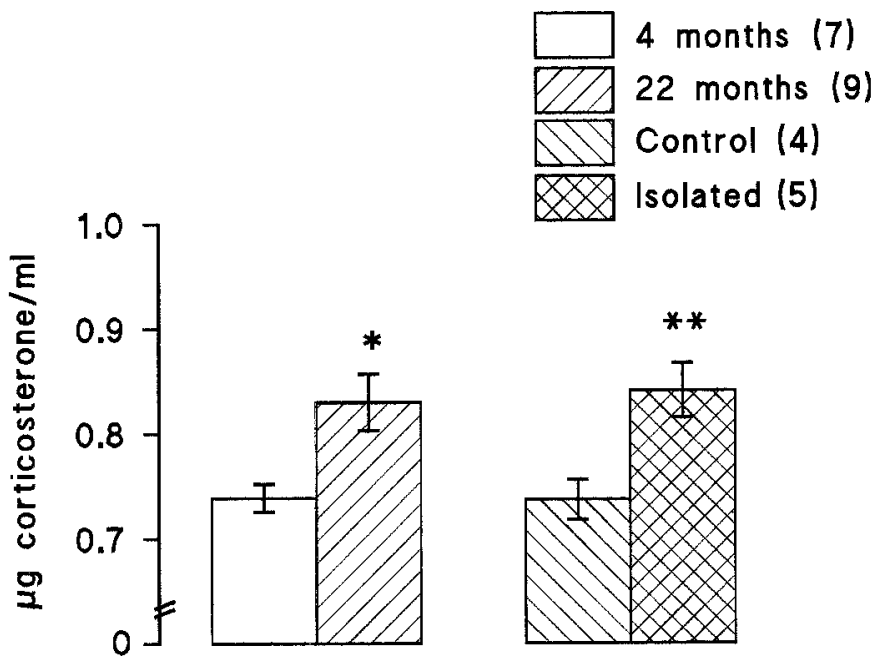

Figure 3. Circulating corticosteroid concentrations were elevated in mildly stressed rats and in aged rats. There was a significant increase in circulating corticosteroids in 22-month-old compared with 4-month-old rats ( $p<0.05$, Student's $t$ test) and similarly in rats that had been housed in isolation, i.e., mildly stressed rats, compared with the control rats that had been housed as a group ( $p<0.01$, Student's $t$ test). Analysis was made in samples obtained from rats at the end of electrophysiological recording in all cases. The number of observations is given in parentheses.

Figure $2 a$ indicates that IL- $1 \beta$ concentration was significantly increased in dentate gyrus prepared from 22-month-old compared with 4-month-old rats ( $p<0.01$, Student's $t$ test).

In a separate series of experiments, six rats were housed as a group, and another six rats were housed in individual cages, a manipulation that has been shown to induce mild stress. To confirm that some stress was incurred in the present experiment, we analyzed circulating corticosteroid levels in serum obtained from these rats at the end of the electrophysiological recording period. This analysis indicated a significant increase in the group of animals housed in isolation, compared with those housed together (Fig. 3; $p<0.01$, Student's $t$ test). We also observed that there was a significant increase in circulating corticosteroids in aged rats compared with young rats (Fig. 3; $p<0.05$, Student's $t$ test). The mean slope of the EPSP in the $10 \mathrm{~min}$ period before tetanic stimulation was greater in the individually housed rats compared with the group-housed rats $(1.05 \pm 0.07$ and $1.52 \pm$ $0.07 \mathrm{mV} / \mathrm{msec}$, respectively; $p<0.05$, Student's $t$ test), but the mean amplitude of the response was similar in both groups $(4.34 \pm 0.23$ and $4.68 \pm 0.18 \mathrm{mV}$ in the individually housed and group-housed rats, respectively).

We report that LTP was impaired in rats that were housed in individual cages compared with rats that were housed as a group; both induction and maintenance of LTP were significantly affected. As a measure of induction of LTP, we assessed the change in EPSP slope in the $2 \mathrm{~min}$ period immediately after tetanic stimulation; these values were $147.38 \pm 4.28$ and $129.30 \pm 4.32 \%$ in the group-housed rats and the individually housed rats, respectively (Fig. $4 ; p<0.05$, Student's $t$ test). The data also indicated that maintenance of LTP was affected; the mean percentage changes in EPSP slope in the last $5 \mathrm{~min}$ of the experiment compared with the $5 \mathrm{~min}$ immediately before tetanic stimulation were $115.42 \pm 0.90$ and $92.35 \pm 0.77 \%$ in the group-housed and individually housed rats, respectively (Fig. $4 b ; p<0.05$, Student's $t$ test). Figure $4 a$ indicates that IL- $1 \beta$ concentration was significantly increased in hippocampus prepared from the individually housed rats compared with the group-housed rats $(p<0.01$, Student's $t$ test).

The data from these three experiments demonstrate that there is a negative correlation between IL- $1 \beta$ concentration and LTP in the dentate gyrus. Analysis of the data from the separate experiments indicate a significant correlation in each case (Fig. 5; $p<0.05$ in the experiments that analyzed changes in aged vs young rats and the experiment that compared the effect of intraventricular injection of saline and IL- $1 \beta ; p<0.001$ in the experiments that analyzed difference between individually housed and group-housed rats). IL- $1 \beta$ concentrations were not obtained in all samples because of technical difficulties; all the matched paired data that we obtained for EPSP slopes and IL- $1 \beta$ concentrations are presented. In vitro analysis revealed that IL-1 $\beta$ induced a significant increase in lipid peroxidation in hippocampal preparations (Fig. $6 ; p<0.001$, Student's $t$ test), and this was reversed by the antioxidant vitamin E, suggesting that the action of IL-1 $\beta$ might require formation of reactive oxygen species. Figure 6 also indicates that IL- $1 \beta$ significantly enhanced reactive oxygen species formation in hippocampus in vitro $(p<0.01$, Student's $t$ test). To assess the possibility that increased endogenous IL- $1 \beta$ might induce lipid peroxidation in vivo, tissue was prepared from hippocampus of saline-injected and IL- $1 \beta$-injected rats and analyzed for lipid peroxidation and membrane arachidonic acid concentration. Figure 7 indicates that intraventricular injection of IL- $1 \beta$ induced a significant increase in lipid peroxidation $(p<0.05$, Student's $t$ test), and this was coupled with a significant decrease in membrane arachidonic acid ( $p<0.001$, Student's $t$ test). A comparison of changes in aged and young rats indicated significant age-related increases in reactive oxygen species formation and lipid peroxidation coupled with an age-related decrease in membrane arachidonic acid concentration (Fig. $8 ; p<0.05$ in the case of reactive oxygen species production; $p<0.01$ in the case of lipid peroxidation).

\section{DISCUSSION}

Our first objective was to establish whether the impairment in LTP in perforant path $\rightarrow$ granule cell synapses, associated with age, stress, or IL- $1 \beta$, might be explained by one common underlying factor: an increase in IL- $1 \beta$ concentration in dentate gyrus. The second objective was to investigate the mechanism by which this increase in IL-1 $\beta$ concentration might exert its inhibitory effect.

The data indicate that intraventricular injection of IL- $1 \beta$ had little effect on induction of LTP in the dentate but inhibited the persistent increase in EPSP slope. Although an inhibitory effect of IL-1 $\beta$ has been described in vitro in CA3 (Katsuki et al., 1990), CA1 (Bellinger et al., 1993), and dentate gyrus (Cunningham et al., 1996), this is the first indication that intraventricular injection of the cytokine inhibits LTP in any area of the hippocampus in vivo. We found that IL- $1 \beta$ concentration in dentate gyrus was significantly increased in rats that had received an intraventricular injection of the cytokine compared with saline-injected rats. The mechanism by which this change is triggered is unknown; injected IL- $1 \beta$ may diffuse from the ventricle to the neighboring dentate gyrus, or it may induce release of IL- $1 \beta$ from neuronal and/or glial cells in the dentate gyrus, as described elsewhere in the CNS (Yao et al., 1990). This question remains to be addressed.

Electrophysiological responses to test shocks were reduced in aged rats compared with young rats, and we observed that there was an age-related decrease in the ability to sustain LTP, as reported previously (Landfield et al., 1978a; Barnes, 1979; Davis et al., 1993; Diana et al., 1995; Lynch and Voss, 1994; McGahon 
(a)

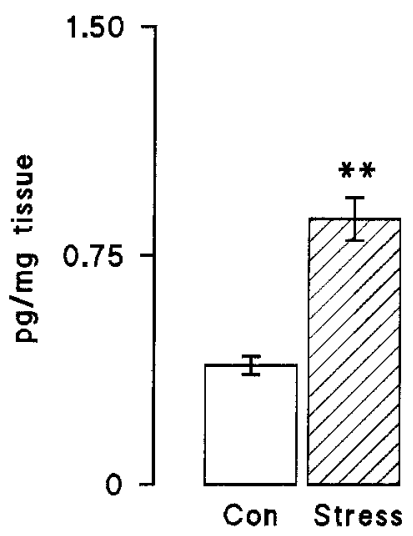

(4)

(5) (b)

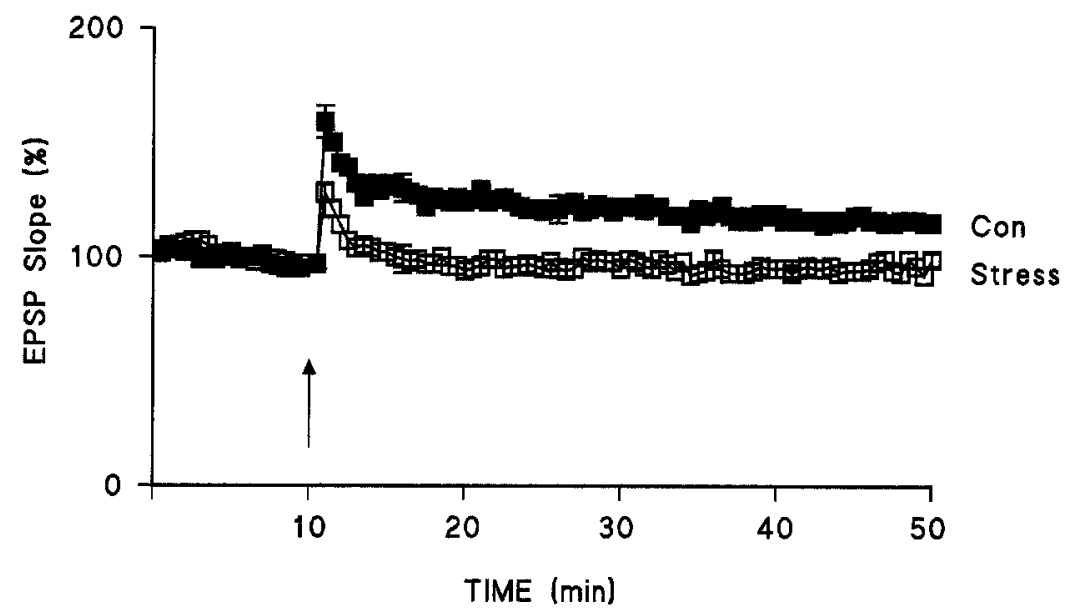

Figure 4. IL-1 $\beta$ concentration in dentate gyrus is increased and LTP is compromised in rats that were mildly stressed by isolation-housing compared with control rats. $a$, IL $-1 \beta$ concentration (picograms per milligram of tissue) was significantly increased ( $p<0.01$, Student's $t$ test; hatched bars) in mildly stressed rats compared with control rats (open bars). Values are mean \pm SEM, and the number of observations is given in parentheses. $b$, Induction of LTP was significantly reduced in the mildly stressed rats compared with the control rats ( $p<0.05$, Student's $t$ test), and the mean percent of EPSP slope returned to baseline levels in $\sim 10 \mathrm{~min}$ in the stressed rats $(n=6)$, whereas it remained elevated for the duration of the experiment in the control rats $(n=4)$. Values are given as mean percent of change in the slope of the EPSP over a 50 min period. Error bars indicating SE are included at 5 min intervals; in some instances these are so small as to be obscured by the symbols.

et al., 1997), although there was no evidence of an age-related change in EPSP slope immediately after tetanic stimulation. The age-related impairment of the ability to sustain LTP correlated with increased IL- $1 \beta$ concentration in dentate gyrus, and although we have reported an age-related increase in IL-1 $\beta$ in hippocampus (Murray and Lynch, 1997), this is the first report of an increase in the dentate gyrus and the first evidence that an increase correlates with impaired LTP.

LTP was impaired in rats that had undergone mild stress compared with control rats. The stress response stimulates an array of changes, including the observed increase in circulating corticosterone that relies on activation of the hypothalamus to increase release of corticotropin-releasing factor. Hypothalamic release of corticotropin-releasing factor is stimulated in vitro by IL-1 (Sapolsky et al., 1987), and because the hippocampus modulates hypothalamo-pituitary function (Landfield and Eldridge, 1994), we argued that an increase in IL- $1 \beta$ in hippocampus might underlie the increase in circulating corticosteroids. We report that in rats that had undergone a mild stress, the increase in circulating corticosterone correlated with increased IL- $1 \beta$ concentration in hippocampus. The observation that circulating corticosteroids and IL-1 $\beta$ concentration in hippocampus were also increased in
(A)

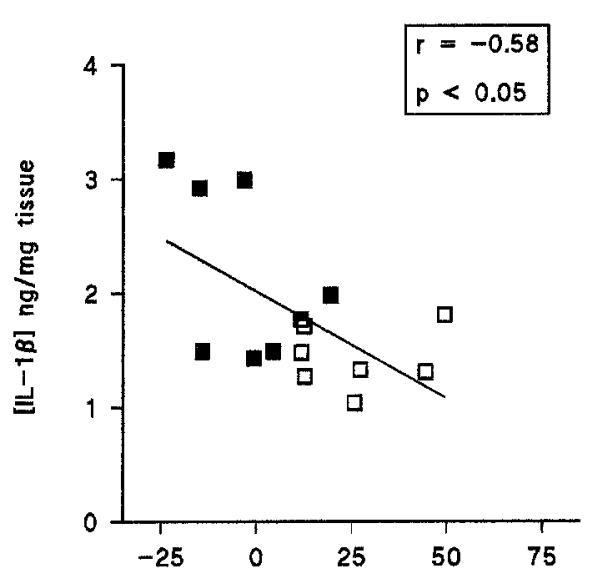

(B)

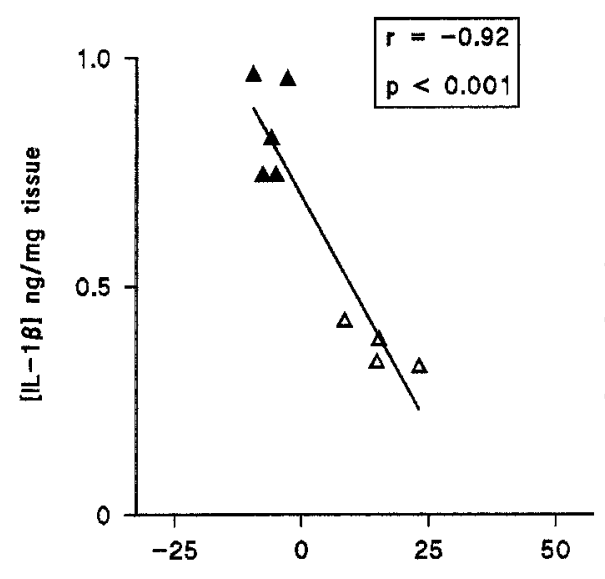

(c)

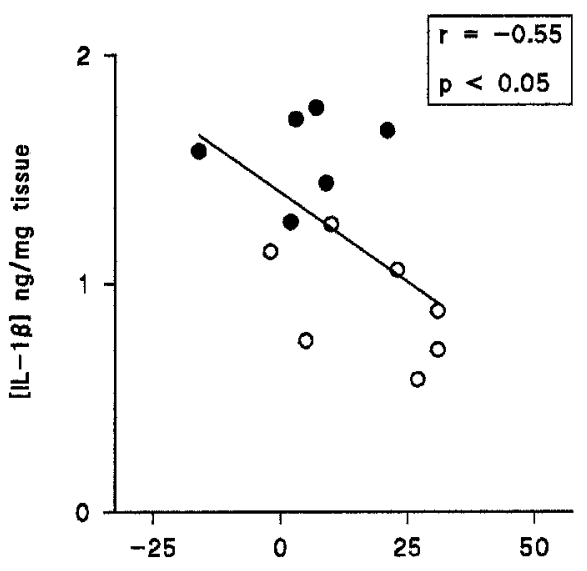

\% CHANGE IN EPSP SLOPE

Figure 5. Maintenance of LTP is inversely proportional to IL-1 $\beta$ concentration in hippocampus. Regression analysis on data from aged rats compared with young $(a)$, individually housed rats compared with group-housed $(b)$, and IL-1 $\beta$-pretreated rats compared with saline-pretreated $(c)$ revealed that there was a statistically significant correlation between IL-1 $\beta$ concentration and the mean percent of change in EPSP slope in the last 5 min of the experiment. Regression $(r)$ and $p$ values are indicated. 


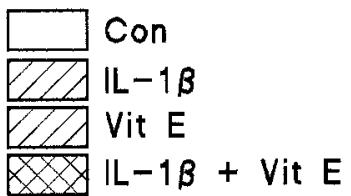

$\operatorname{LP}(n=6)$
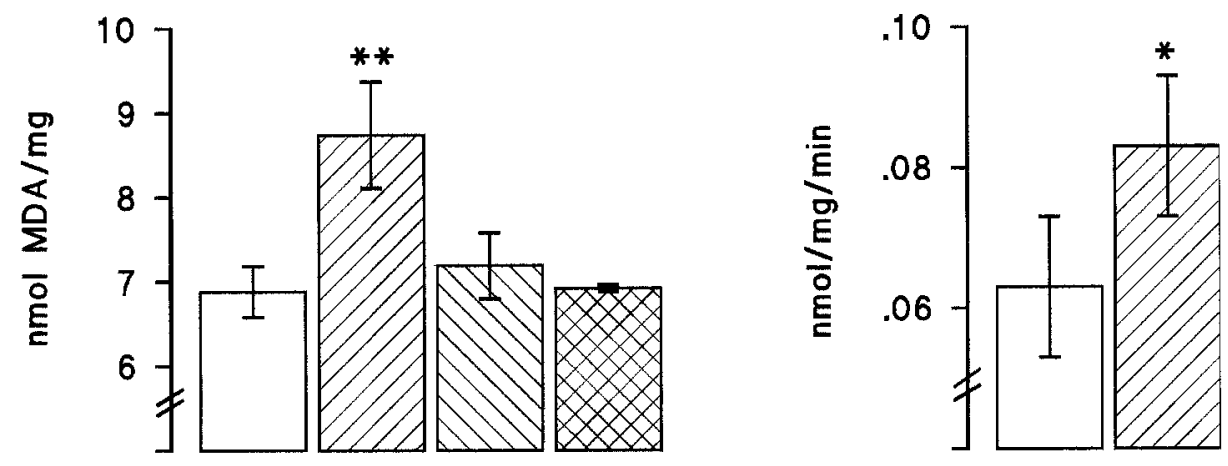

Figure 6. IL-1 $\beta$ induces lipid peroxidation and reactive oxygen species production in hippocampal tissue in vitro. IL-1 $\beta(3.5 \mathrm{ng} / \mathrm{ml})$ significantly increased lipid peroxidation in hippocampal homogenate $(p<0.001)$ and this was inhibited by vitamin $\mathrm{E}(200 \mu \mathrm{M})$. IL-1 $\beta$ also significantly increased formation of reactive oxygen species $(p<0.01$, Student's $t$ test). The number of observations is given in parentheses. parallel, in aged rats compared with young rats, strengthens the hypothesis that a causal relationship between the two parameters exists. However, the interplay between circulating glucocorticoids and cytokines is complex with evidence of feedback control; thus, whereas IL-1 $\beta$ stimulates the hypothalamo-pituitary-adrenal axis, the anti-inflammatory actions of glucocorticoids include inhibition of cytokine synthesis in brain (Rothwell et al., 1996). The question of the interplay between circulating corticosteroids and IL-1 $\beta$ concentration in hippocampus remains to be addressed; the data presented indicate a causal link between these parameters but do not allow speculation concerning feedback control.

One consequence of behavioral stress is impaired LTP (Foy et al., 1987; Diamond et al., 1990; Landfield and Eldridge, 1994; Xu et al., 1997), which has been attributed to an increase in circulating corticosteroids and is inversely proportional to ability of rats to sustain LTP (Foy et al., 1987). In support of these observations, the present findings indicate an inverse relationship between circulating corticosteroids and impaired LTP in two groups of animals, i.e., aged rats and behaviorally stressed rats. It is noteworthy that analysis of the effect of stress on primed burst poten- tiation revealed a more complex relationship between potentiation and circulating corticosteroids, such that at low concentrations a direct relationship was observed and at high concentrations an inverse relationship existed (Diamond et al., 1992).

We demonstrated that increased IL- $1 \beta$ concentration is a common feature of impaired LTP in three circumstances, after intraventricular injection of IL- $1 \beta$, in aged rats and in stressed rats, but although a significant inverse correlation between IL- $1 \beta$ concentration and ability to sustain LTP was observed, it would be unreasonable to suggest that other factors do not contribute to impairments in LTP in aged and stressed rats. These data are consistent with the hypothesis that although limited exposure of tissue to low concentrations of IL-1 $\beta$ may be neuroprotective, prolonged exposure to higher concentrations may induce degenerative changes (Hopkins and Rothwell, 1995; Rothwell and Hopkins, 1995). It is of interest that increased expression of IL-1 has been reported in Alzheimer's disease and Down's syndrome (Griffin et al., 1989), and it is conceivable that the age-related increase in IL- $1 \beta$ in dentate gyrus observed in this study may be indicative of degenerative changes in the rat brain, one manifestation of which is an impairment in LTP.

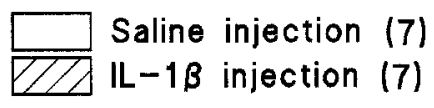

Arachidonic acid

\section{Lipid Peroxidation}

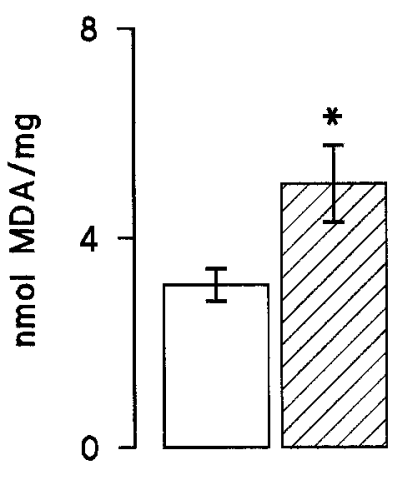

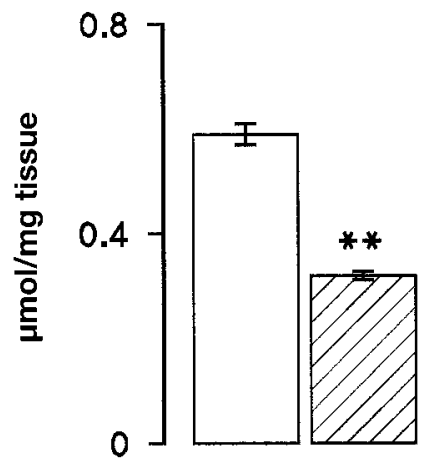

Figure 7. Intraventricular injection of IL- $1 \beta$ increases lipid peroxidation and decreases membrane arachidonic acid concentration in hippocampus. Untetanized dentate gyri from the saline-injected and IL- $1 \beta$-injected rats were dissected at the end of the period of electrophysiological recording, stored as described in Materials and Methods, and analyzed for lipid peroxidation and membrane arachidonic acid concentration. There was a significant increase in lipid peroxidation $(p<0.05$, Student's $t$ test), and this was accompanied by a significant decrease in membrane arachidonic acid concentration $(p<0.001$, Student's $t$ test). The number of observations is given in parentheses. 
Figure 8. Aging was associated with increased reactive oxygen species formation and lipid peroxidation, coupled with a decrease in membrane arachidonic acid. Untetanized dentate gyri from 4- and 22-month-old rats were dissected at the end of the period of electrophysiological recording, stored as described in Materials and Methods, and analyzed for reactive oxygen species production, lipid peroxidation, and membrane arachidonic acid concentration. Reactive oxygen species production and lipid peroxidation were significantly increased in 22-month-old compared with 4-month-old rats $(p<$ 0.05 and $p<0.01$, respectively, Student's $t$ test). Mean arachidonic acid concentration was significantly decreased in 22-month-old compared with 4-month-old rats $(p<0.01$, Student's $t$ test). The number of observations is given in parentheses.

\section{REACTIVE OXYGEN SPECIES}

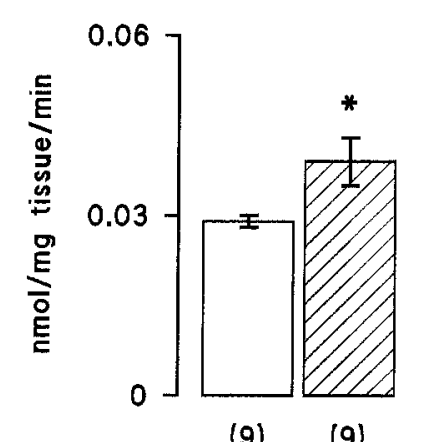

(9)
(9)
LIPID PEROXIDATION

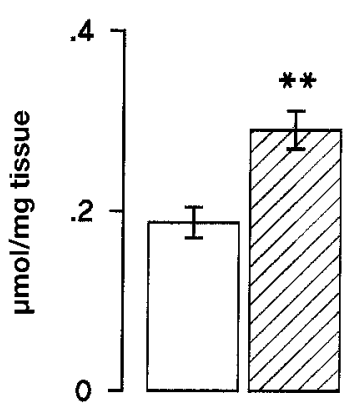

(6)

(6)

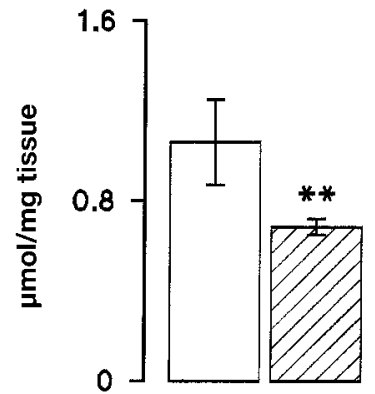

(6)
4 months

22 months
Previous reports have indicated that impaired LTP in aged rats was associated with decreased membrane arachidonic acid concentration (Lynch and Voss, 1994), restoration of which reversed the age-related impairment in LTP (McGahon et al., 1997). Although the trigger responsible for inducing the decrease in membrane arachidonic acid has not been identified, depletion of polyunsaturated fatty acids is a known consequence of lipid peroxidation (Rehncrona et al., 1980; Yu et al., 1992; Nagy, 1994). In vitro analysis indicated that lipid peroxidation was increased by IL- $1 \beta$, and this effect was inhibited by the antioxidant vitamin E, suggesting that the IL- $1 \beta$-induced effect was mediated by production of reactive oxygen species formation, supporting data previously obtained in macrophages (Nathan and Tsunawaki, 1986; Harrison and Murphy, 1995). Data presented here confirm the stimulatory effect of IL- $1 \beta$ on reactive oxygen species production in hippocampus. We probed the changes that accompany the increase in IL-1 $\beta$ concentration in vivo and established that there was a parallel increase in lipid peroxidation and decrease in membrane arachidonic acid concentration in hippocampus of aged rats. Similar correlations were observed in rats injected intraventricularly with IL- $1 \beta$. These observations are consistent with the hypothesis that IL-1 $\beta$, by inducing lipid peroxidation, may be the endogenous trigger for the age-related decrease in membrane arachidonic acid concentration.

Although neuronal damage has been associated with enhanced plasma levels of corticosterone (Landfield and Eldridge, 1994), accumulation of oxidative damage by free radicals is readily observed in the aged brain (Choi and Yu, 1995). Our data indicate that there was an increase in production of reactive oxygen species in dentate gyrus prepared from aged rats when compared with young, and in mildly stressed rats when compared with control. Although IL- $1 \beta$ increases formation of reactive oxygen species in hippocampus in vitro, we observed that it also triggers this effect in vivo. This increase in reactive oxygen species may be a direct effect of IL-1 $1 \beta$ or it may derive from IL- $1 \beta$ induced peroxidation of arachidonic acid. Oxygen radicals can increase IL-1 $\beta$ in hippocampus in vitro (C. A. Murray and M. A. Lynch, unpublished observations), suggesting that a positive feedback loop exists in which a spiral of potentially detrimental reactions can be triggered by IL- $1 \beta$. The findings of this study permit us to propose that the age- and stress-related increase in reactive oxygen species formation in hippocampus may be conse- quent on increased endogenous IL- $1 \beta$, which we propose is the salient feature of the free radical hypothesis of aging.

The inhibitory effect of IL-1 on LTP in vitro has been linked with an inhibitory effect on glutamate release (Murray et al., 1997) and protein kinase C (Plata-Salaman and ffrench-Mullen, 1994), but the molecular mechanism by which IL- $1 \beta$ induces these changes is unknown. An IL- $1 \beta$-associated decrease in calcium influx in hippocampus has also been described (PlataSalaman and ffrench-Mullen, 1994; Cunningham et al., 1996), although recent evidence has indicated that higher concentrations of IL-1 $\beta$ increased intracellular calcium concentrations (Campbell and Lynch, 1998). This finding is of interest because there is a good deal of evidence suggesting that intracellular calcium concentration is increased in hippocampal neurons of aged rats (e.g., Landfield and Eldridge, 1994). We propose that IL-1 $\beta$ induces lipid peroxidation that decreases membrane arachidonic acid, consequently affecting membrane fluidity that will impact on membrane-associated functions, and may therefore explain the IL-1-induced effects on transmitter release, channel activity, and enzyme activity. We propose that the changes leading to increased membrane rigidity are triggered by IL- $1 \beta$, and therefore, that the age-related increase in endogenous IL- $1 \beta$ in hippocampus may be the precursor to the membrane hypothesis of aging. Our findings directly couple increased circulating corticosterone in two physiological conditions, age and stress, with increased endogenous IL- $1 \beta$ concentration in hippocampus, and therefore provide evidence that the glucocorticoid theory of aging might also be explained by elevated levels of the cytokine.

\section{REFERENCES}

Ban E, Milon G, Prudhomme N, Fillion G, Haour F (1991) Receptors for interleukin-1 $(\alpha$ and $\beta$ ) in mouse brain: mapping and neuronal localization in hippocampus. Neuroscience 43:21-30.

Barnes CA (1979) Memory deficits associated with senescence: a neurophysiological and behavioural study in the rat. J Comp Physiol Psychol 93:74-104.

Bellinger FP, Madamba S, Siggins GR (1993) Interleukin- $1 \beta$ inhibits synaptic strength and long-term potentiation in the rat CA1 hippocampus. Brain Res 628:227-234.

Bodnoff SR, Humphreys AG, Lehman JC, Diamond DM, Rose GM, Meaney M (1995) Enduring effects of chronic corticosterone treatment on spatial learning, synaptic plasticity, and hippocampal neuropathology in young and mid-aged rats. J Neurosci 15:61-69.

Bradford MM (1976) A rapid and sensitive method for the quantitation 
of microgram quantities of proteins utilizing the principle of protein dye binding. Anal Biochem 72:248-254.

Campbell, V and Lynch, MA (1998) Biphasic modulation of intracellular calcium by interleukin- $1 \beta$ in rat cortical synaptosomes. J. Physiol (Lond), in press.

Choi J, Yu BP (1995) Brain synaptosomal aging: free radicals and membrane fluidity. Free Radic Biol Med 18:133-139.

Cunningham AJ, Murray CA, O’Neill LAJ, Lynch MA, O’Connor JJ (1996) Interleukin- $1 \beta$ (IL-1 $\beta$ ) and tumour necrosis factor (TNF) inhibit long-term potentiation in the rat dentate gyrus in vitro. Neurosci Lett 203:1-4.

Cunningham Jr ET, Wada E, Carter DB, Tracey DE, Battey JF, De Souza EB (1992) In situ histochemical localization of Type 1 interleukin-1 receptor mRNA in the CNS, pituitary, and adrenal gland of the mouse. J Neurosci 12:1101-1114.

Dascombe MJ, Rothwell NJ, Sagay BO, Stock MJ (1989) Pyrogenic and thermogenic effects of interleukin- $1 \beta$ in the rat. Am $\mathrm{J}$ Physiol 256:E7-E11.

Davis S, Markowska AL, Wenk GL, Barnes CA (1993) Acetyl-Lcarnitine: behavioural, electrophysiological and neurochemical effects. Neurobiol Aging 14:107-115.

Diamond DM, Bennett MC, Stevens KE, Wilson RL, Rose GM (1990) Exposure to a novel environment interferes with the induction of hippocampal primed burst potentiation in the behaving rat. Psychobiology 18:273-281.

Diamond DM, Bennett MC, Fleshner M, Rose GM (1992) Inverted-U relationship between the level of peripheral corticosterone and the magnitude of the hippocampal primed burst potentiation. Hippocampus 2:421-430.

Diana G, Domenici MR, Scotti de Carolis A, Loizzo A, Sagratella S (1995) Reduced hippocampal CA1 $\mathrm{Ca}^{2+}$-induced long-term potentiation is associated with age-dependent impairment of spatial learning. Brain Res 686:107-110.

Ericsson A, Liu C, Hart RP, Sawchenko PF (1995) Type I interleukin-1 receptor in the rat brain: distribution, regulation and relationship to sites of IL-1-induced cellular activation. J Comp Neurol 361:681-698.

Farrar WL, Hill JM, Harel-Bellan A, Vinocour M (1987) The immune logical brain. Immunol Rev 100:361-378.

Fontana A, Weber E, Dayer JM (1984) Synthesis of interleukin-1/ endogenous pyrogen in the brain of endotoxin-treated mice: a step in fever induction? J Immunol 19:1696-1698.

Foy MR, Stanton ME, Levine S, Thompson RF (1987) Behavioural stress impairs long-term potentiation in rodent hippocampus. Behav Neural Biol 48:138-149.

Giulian D, Baker TJ, Shih L-CN, Lachman LB (1986) Interleukin-1 of the central nervous system is produced by ameboid microglia. J Exp Med 164:594-604.

Griffin WST, Stanley LC, Ling C, White L, MacLeod V, Perrot LJ, White CL III, Araoz C (1989) Brain interleukin 1 and S-100 immunoreactivity are elevated in Down's syndrome and Alzheimer's disease. Proc Natl Acad Sci USA 86:7611-7615.

Haan EA, Bowen DM (1981) Protection of neocortical prisms from freeze-thaw injury by dimethylsulphoxide. J Neurochem 37:243-246.

Harman D (1956) Aging: a theory based on free radical and radiation chemistry. J Gerontol 11:298-300.

Harrison KA, Murphy RC (1995) Isoleukotrienes are biologically active free radical products of lipid peroxidation. J Biol Chem 270:17273-17278.

Hopkins SJ, Rothwell NJ (1995) Cytokines and the nervous system. I. Expression and recognition. Trends Neurosci 18:83-88.

Katsuki H, Nakai S, Hirai Y, Akaji K, Kiso Y, Satoh M (1990) Interleukin- $1 \beta$ inhibits long-term potentiation in the CA3 region of mouse hippocampal slices. Eur J Pharmacol 181:323-326.

Landfield PW, Eldridge C (1994) The glucocorticoid hypothesis of agerelated hippocampal neurodegeneration: role of dysregulated intraneuronal calcium. Ann NY Acad Sci 746:308-326.

Landfield PW, Waymire JC, Lynch G (1978a) Hippocampal aging and adrenocorticoids: quantitative correlations. Science 202:1098-1102.

Landfield PW, McGaugh JL, Lynch G (1978b) Impaired synaptic potentiation processes in the hippocampus of aged, memory-deficient rats. Brain Res 150:85-101.

Lebel CP, Bondy SC (1990) Sensitive and rapid quantitation of oxygen reactive species formation in rat synaptosomes. Neurochem Int 17:435-440.

Lechan RM, Toni R, Clark BD, Cannon JG, Shaw AR, Dinarello CA,
Reichlin S (1990) Immunoreactive interleukin-1 $\beta$ localization in the rat forebrain. Brain Res 514:135-140.

Lynch MA (1997) Age-related changes in synaptic plasticity in rat hippocampus. J Physiol (Lond) 501:5S-6S

Lynch MA, Voss KL (1994) Membrane arachidonic acid concentration correlates with age and induction of long-term potentiation in the dentate gyrus of the rat. Eur J Neurosci 6:1008-1014.

McGahon B, Lynch MA (1996) The synergism between metabotropic glutamate receptor activation and arachidonic acid on glutamate release is occluded by induction of long-term potentiation in the dentate gyrus. Neuroscience 72:847-855.

McGahon B, Clements MP, Lynch MA (1997) The ability of aged rats to sustain LTP is restored when the age-related increase in membrane arachidonic acid is reversed. Neuroscience 81:9-16.

Miwa H, Yamamoto M, Nishida T (1986) Assay of free and total fatty acids (as 2-nitrophenylhydrazides) by high performance liquid chromatography. Clin Chim Acta 55:95-102.

Mo Z-L, Katafuchi T, Hori T (1996) Effects of IL-1 $\beta$ on neuronal activities in the dorsal nucleus of the vagus in rat brain slices. Brain Res Bull 41:249-255.

Murray C, Lynch MA (1997) Impaired ability of aged animals to sustain long-term potentiation may result from increased hippocampal expression of interleukin-1 $\beta$. J Physiol (Lond) 501:87P.

Murray CA, McGahon BM, McBennett S, Lynch MA (1997) Interleukin- $1 \beta$ inhibits glutamate release in hippocampus of young, but not aged, rats. Neurobiol Aging 18:343-348.

Nagy Zs-I (1994) The membrane hypothesis of aging. Boca Raton, FL: CRC.

Nathan CF, Tsunawaki S (1986) Secretion of toxic oxygen products by macrophages: regulatory cytokines and their effects on the oxidase. Ciba Found Symp 118:211-230.

Ohkawa H, Ohishi N, Yagi K (1979) Assay for lipid peroxides in animal tissues by thiobarbituric acid reaction. Anal Biochem 95:351-358.

Parnet P, Amindari S, Wu C, Brunke-Reese D, Goujon E, Weyhenmeyer JA, Danzer R, Kelley KW (1994) Expression of type I and type II interleukin-1 receptors in mouse brain. Mol Brain Res 27:63-70.

Pellmar TC, Hollinden GE, Sarvey JM (1991) Free radicals accelerate the decay of long-term potentiation in field CA1 of the guinea-pig hippocampus. Neuroscience 44:353-359.

Plata-Salaman CR, ffrench-Mullen JMH (1994) Interleukin-1 $\beta$ inhibits $\mathrm{Ca}^{2+}$ channel currents in hippocampal neurons through protein kinase C. Eur J Pharmacol 266:1-10.

Plata-Salaman CR, Oomura Y, Kai Y (1988) Tumour necrosis factor and interleukin-1 $\beta$ : suppression of food intake by direct action in the central nervous system. Brain Res 448:106-114.

Rada P, Mark GP, Vitek MP, Manago RM, Blume AJ, Beer B, Hoebel, BG (1991) Interleukin-1 $\beta$ decreases acetylcholine measured by microdialysis in the hippocampus of freely moving rats. Brain Res 550:287-290.

Rehncrona S, Smith DS, Akesson B, Westerberg E, Siesjö BK (1980) Peroxidative changes in cortical fatty acids and phospholipids, as characterized during $\mathrm{Fe}^{2+}$-and ascorbic acid-stimulated lipid peroxidation in vitro. J Neurochem 34:1630-1638.

Rothwell NJ, Hopkins SJ (1995) Cytokines and the nervous system. II. Actions and mechanisms of action. Trends Neurosci 18:130-136.

Rothwell NJ, Luheshi G, Toulmond S (1996) Cytokines and their receptors in the central nervous system: physiology, pharmacology and pathology. Pharmacol Ther 69:85-95.

Sapolsky R, Rivier C, Yamamoto G, Plotsky P, Vale W (1987) Interleukin-1 stimulates the secretion of hypothalamic corticotrophinreleasing factor. Science 238:522-524.

Sumoski W, Baquerizo H, Rabinovitch A (1989) Oxygen free radical scavengers protect rat islet cells from damage by cytokines. Diabetologia 32:792-796.

Takao T, Tracey DE, Mitchell WM, De Souza EB (1990) Interleukin-1 receptors in mouse brain: characterization and neuronal localization. Endocrinology 127:3070-3078.

Xu L, Anwyl R, Rowan MJ (1997) Behavioural stress facilitates the induction of long-term depression in the hippocampus. Nature 387:497-500.

Yao J, Keri J, Taffs RE, Colton CA (1992) Characterization of interleukin-1 production by microglia in culture. Brain Res 591:88-93.

Yu BP, Suescun EA, Yang SY (1992) Effect of age-related lipid peroxidation on membrane fluidity and phospholipase $\mathrm{A}_{2}$ : modulation by dietary restriction. Mech Ageing Dev 65:17-33. 